$* * *$

1. Офшор, Энциклопедический словарь // [Электронный pecypc] URL: https://dic.academic.ru/dic.nsf/es/84776 (дата обращения: 16.03.2021).

2. Что такое офшорные зоны. Издательство "Главная книга", 05.03.2021 // [Электронный ресурс] Доступ из справ.-правовой системы «КонсультантПлюс».

3. Письмо ФНС России от 22.12.2015 N OA-4-17/22482@ "О взаимной административной помощи по налоговым делам и международном обмене налоговой информацией" // [Электронный ресурс] Доступ из справ.-правовой системы «КонсультантПлюс».

4. Гурьянова Н.В. Офшорные зоны // СПС КонсультантПлюс. 2021.

5. Андрианова Н.Г. Перечень офшорных зон в российском праве // Юрист. 2020. N 11. С. 49 - 54.

6. Федеральный закон от 24.11.2014 N 376-Ф3 (ред. от 12.11.2018) "О внесении изменений в части первую и вторую Налогового кодекса Российской Федерации (в части налогообложения прибыли контролируемых иностранных компаний и доходов иностранных организаций)" // Собрание законодательства РФ. 2014. N 48. ст. 6657.

7. Жильцова Ю.В., Саванина И.Р. Офшорные зоны и бегство капиталов: причины и инструменты дестимулирования // Бухгалтерский учет в бюджетных и некоммерческих организациях. 2020. N 22. C. 28 - 39.

8. Федеральный закон от 15.02.2016 N 23-Ф3 "О внесении изменений в Бюджетный кодекс Российской Федерации" // Собрание законодательства РФ. 2016. № 7. ст. 911.

9. Статистический бюллетень Банка России № 9 (292), 2017 // [Электронный ресурс] URL: https://cbr.ru/Collection/Collection/File/7522/BBs1709r.pdf (дата обращения: 17.03.2021).

10. Чистый отток капитала в январе снизился на $12 \%, 9$ февраля 2021 // [Электронный ресурс] URL: https://tass.ru/ekonomika/10659551 (дата обращения: 17.03.2021).

11. Смирнов Е.Н. Офшорные схемы в современном международном движении капитала: особенности и механизмы противодействия // Вестник Евразийской науки, 2018 №5, https://esj.today/PDF/66ECVN518.pdf (доступ свободный). Загл. с экрана. Яз. рус., англ.

12. URL: https://cloudfront-files-1.publicintegrity.org/offshoreleaks/data-csv.zip (дата обращения: 18.03.2021).

13. Панамская дыра: интерактивная карта офшоров, 26.05.2016 // [Электронный ресурc] URL: https://www.forbes.ru/kompanii/321345-panamskaya-dyra-interaktivnaya-karta-ofshorov (дата обращения: 18.03.2021).

14. Интерактивная карта офшоров // [Электронный pecypc] URL: http://www.forbes.ru/sp_data/2016/offshore/maps/map01.html (дата обращения: 18.03.2021).

15. Фаткина Е.В. Реализация требований Закона США "О налогообложении иностранных счетов" (FATCA): проблема соблюдения банковской тайны // Банковское право. 2015. N 3. С. 51 - 57.

16. Основные направления бюджетной, налоговой и таможенно-тарифной политики на 2021 год и на плановый период 2022 и 2023 годов (утв. Минфином России) // [Электронный ресурс] СПС «КонсультантПлюс».

\title{
Кузьмин В.A.
}

Особенности нормативно-правового регулирования инвестиционной безопасности Российский государственный университет правосудия Северо-Кавказский филиал

doi: $10.18411 / \mathrm{sr}-10-04-2021-80$

(Россия, Краснодар)

\section{Аннотация}

Проанализированы и структурированы нормативные правовые акты, регулирующие финансовые инструменты в контексте инвестиционной деятельности физических лиц на финансовом рынке. Обозначены конкретные меры регулятора (Банк России) по защите потребителей от возможных финансовых мошенничеств в условиях ухудшения инвестиционного климата российской экономики по причине мирового кризиса, вызванного коронавирусной инфекцией.

Ключевые слова: инвестиции, ценные бумаги, сбережения, финансовый рынок, квалифицированные и неквалифицированные участники финансового рынка, индивидуальный инвестиционный счет. 
Актуальность темы исследования обусловлена необходимостью изучения и анализа отдельных правовых норм, регулирующих инвестиционную безопасность, поскольку в настоящее время законодательная база достаточно широкая и у правоприменителя возникают сложности в понимании степени государственной защиты инвестиций, что влечет низкий уровень инвестирования среди физических лиц.

Банк России согласно Федеральному закону «О Центральном банке Российской Федерации» от 10 июля 2002 г. № 86-Ф3 [5] отвечает за надзор, регулирование и развитие во всех секторах финансового рынка: банковской системы, страхового сектора, коллективных инвестиций и пенсионных накоплений, рынка ценных бумаг, микрофинансирования. Банк России также отвечает за инфраструктуру финансового рынка - деятельность рейтинговых агентств, бирж, депозитариев и других участников.

Теперь обратим внимание на такое понятие, как «инвестиционные вложения» и его трактовку в действующих нормативных правовых актах.

Статьей 1 Федерального закона «Об инвестиционной деятельности в Российской Федерации, осуществляемой в форме капитальных вложений» от 25 февраля 1999 г. № 39-Ф3 [8] установлены следующие понятия: «Инвестиции - денежные средства, ценные бумаги, иное имущество, в том числе имущественные права, иные права, имеющие денежную оценку, вкладываемые в объекты предпринимательской и (или) иной деятельности в целях получения прибыли и (или) достижения иного полезного эффекта» и «инвестиционная деятельность - вложение инвестиций и осуществление практических действий в целях получения прибыли и (или) достижения иного полезного эффекта».

Таким образом, определившись с понятийным аппаратом, перейдем к ответу на самый главный вопрос: что и каким образом граждане могут инвестировать на финансовом рынке?

Для экономики рыночного типа инвестирование как «процесс» является не только многогранным, но и сложным явлением. Происходит взаимодействие многих участников финансового рынка.

Если участников классифицировать по принципу спроса и предложения, выделить можно два основных класса: продавцы и покупатели, каждый из которых так же многогранен, как и сам процесс инвестирования. Для наглядного восприятия предлагаем воспользоваться схематично-табличным представлением участников финансового рынка, разработанным Банком России.

Из представленной схемы видно, что на финансовом рынке страны инвестиционные ресурсы могут быть как внутренними, так и внешними.

Для простоты понимания: к внутренним источникам инвестиций отнесем собственные средства инвестора, а к внешним - все остальные.

Поскольку предметом нашего исследования является правовое регулирование инвестиционных вложений именно физических лиц на российском финансовом рынке, то в первую очередь обратимся к тем нормативным правовым актам, которые необходимо знать каждому гражданину, намеревающемуся заняться инвестированием.

Глава 7 Гражданского кодекса Российской Федерации [1] (часть первая) содержит определение ценной бумаги: «...акция, вексель, закладная, инвестиционный пай инвестиционного фонда, коносамент, облигация, чек и иные ценные бумаги...». Данная глава посвящена классификации ценных бумаг и общим вопросам правового регулирования отношений, связанных с их оборотом.

Особого внимания заслуживает Федеральный закон «О рынке ценных бумаг» от 22 апреля 1996 г. № 39-Ф3 [7], который за время своего действия претерпел множество изменений и дополнений, в особенности за прошедшие пять лет. Почему мы считаем его особенным или даже основным? Именно данным Законом в январе 2015 г. было введено новое понятие — индивидуальный инвестиционный счет (ИИС): «...счет внутреннего учета, который предназначен для обособленного учета денежных средств, 
ценных бумаг физического лица, обязательств по договорам, заключенным за счет указанного клиента», который позволил физическим лицам инвестировать с возможностью получения налогового вычета.

Со своего дохода гражданин не уплачивает налог на доходы физических лиц, но лишь при определенных условиях. Законом о фондовом рынке предусмотрено постепенное замещение ценных бумаг на бездокументарные. Введены понятия «бессрочные облигации» и «привилегированные акции с преимуществом в очередности получения дивидендов».

В статье 51.2 Ф3 «О рынке ценных бумаг» «Квалифицированные инвесторы» также про изошли изменения, а именно, пунктом 9 ими признается физическое лицо для получения возможности инвестирования с использованием инвестиционной платформы.

Следует обратить внимание на то, что более 20 лет назад был принят Федеральный закон «О защите прав и законных интересов инвесторов на рынке ценных бумаг» от 5 февраля 1999 г. № 46-Ф3.

В статье 1 указанного Закона сформулированы его цели: «...обеспечение государственной и общественной защиты прав и законных интересов физических и юридических лиц, объектом инвестирования которых являются эмиссионные ценные бумаги (далее - инвесторы), а также определение порядка выплаты компенсаций и предоставления иных форм возмещения ущерба инвесторам - физическим лицам, причиненного противоправными действиями эмитентов и других участников рынка ценных бумаг (далее - профессиональные участники) на рынке ценных бумаг».

В конце 2001 г. принят Федеральный закон «Об инвестиционных фондах» от 29 октября 2001 г. № 156-Ф3 [4], который регулирует экономические отношения, возникшие в сфере привлечения денег или других активов при помощи размещения акций и подписания договоров управления ими с целью их дальнейшего вложения в иные экономические объекты. Управление имуществом фонда осуществляется в интересах инвестора от лица управляющего.

В статье 10 Ф3 «Об инвестиционных фондах» сформировано понятие паевого инвестиционного фонда «...обособленный имущественный комплекс, состоящий из имущества, переданного в доверительное управление управляющей компании учредителем (учредителями) доверительного управления с условием объединения этого имущества с имуществом иных учредителей доверительного управления, и из имущества, полученного в процессе такого управления, доля в праве собственности на которое удостоверяется ценной бумагой, выдаваемой управляющей компанией».

В статье 14 дано понятие инвестиционного пая, который является «...именной ценной бумагой, удостоверяющей долю его владельца в праве собственности на имущество, составляющее паевой инвестиционный фонд, право требовать от управляющей компании надлежащего доверительного управления паевым инвестиционным фондом, право на получение денежной компенсации при прекращении договора доверительного управления паевым инвестиционным фондом со всеми владельцами инвестиционных паев этого фонда (прекращении паевого инвестиционного фонда)».

Одним из законов, разработанных и принятых в интересах физических лиц в начале нового тысячелетия, стал Федеральный закон «Об инвестировании средств для финансирования накопительной части трудовой пенсии» от 24 июля 2002 г. № 111-ФЗ. Закон включает 43 статьи, определяющих особенности осуществления операций по накоплению и инвестированию пенсионных средств, призван регулировать операции в сфере формирования накопительной части пенсии и ее возможное дальнейшее инвестирование, а также в нем конкретизирована информация об особенностях 
контроля операций по формированию пенсионных накоплений со стороны государственных органов и общества.

В августе 2019 г. вступил в силу Федеральный закон «О привлечении инвестиций с использованием инвестиционных платформ и о внесении изменений в отдельные законодательные акты Российской Федерации» от 2 августа 2019 г. № 259Ф3.

Обратим внимание на ст. 7 данного Закона, в которой отражены особенности инвестирования физическими лицами. Так, физическое лицо получает возможность использовать любые инвестиционные платформы для инвестирования с оговоркой «...не более 600 тысяч рублей» «...в течение одного календарного года». Согласно той же статье ограничения не распространяются, если: гражданин (физическое лицо) является ИП (индивидуальным предпринимателем) либо признан оператором инвестиционной платформы квалифицированным инвестором.

Учитывая разделение физического лица на ИП и отдельного гражданина, мы понимаем (и это прописано в Законе), что от гражданина при использовании инвестиционной платформы не требуется государственной регистрации в качестве индивидуального предпринимателя;

физическое лицо приобретает утилитарные цифровые права по договору инвестирования, который заключен с ПАО (публичным акционерным обществом).

В Законе также имеются ограничения для привлечения денежных средств одним лицом, их сумма не должна превышать 1 млрд руб. Установлены и требования к самим инвестиционным платформам: обязательное включение в реестр Банка России и наличие собственного капитала в размере не менее 5 млн руб.

Финансовый рынок есть ни что иное, как система отношений между поставщиками и покупателями финансовых услуг, которая не может полноценно существовать без социального капитала (свободных денежных средств граждан), а гражданин, в свою очередь, без доверия к его инструментам и услугам будет вести себя достаточно консервативно и, как следствие, не произойдет того ускоренного экономического развития, которого все ждут.

На сегодняшний день Банк России не просто заинтересован в развитии такого доверия, но и принимает в этом активное участие (в том числе реализует программу «Финансовая грамотность населения»). В целях формирования на финансовом рынке доверительных отношений меняется не только законодательная база, но и стратегическое направление развития финансовой инфраструктуры:

- сокращение транзакционных издержек рынка, направленных на защиту от недобросовестного поведения; итогом таких действий будет снижение необходимости надзорных действий со стороны Банка России;

- защита средств кредиторов и вкладчиков, что возможно только при укреплении и доверии к национальной валюте, платежным системам и технологиям на рынке, а также финансовой устойчивости организаций;

- борьба с манипулированием, созданием барьеров для недобросовестной, незаконной (безлицензионной) деятельности. Итогом такой борьбы должно стать устранение преимуществ таких игроков перед добросовестными участниками рынка, для этого внедряются элементы корпоративной культуры, где приоритетом являются интересы клиента;

- создание информационной прозрачности, необходимой для понимания процесса ценообразования и восприятия финансового продукта.

Перечисленные меры направлены на рост и развитие активности населения в использовании услуг финансового рынка. Банк России занимает активную позицию по защите потребителей от возможных злоупотреблений продавцами финансовых услуг. 
Регулятор совместно с участниками финансового рынка в 2017 г. разработал концепцию системы квалификации инвесторов, но на сегодняшний день вокруг нее много споров и дискуссий. Данная концепция является частью Закона о рынке ценных бумаг в аспекте введения регулирования категорий инвесторов - физических лиц.

В конце июля 2020 г. Президентом России был подписан закон о категоризации инвесторов - Федеральный закон «О внесении изменений в Федеральный закон «О рынке ценных бумаг» и отдельные законодательные акты Российской Федерации» от 31 июля 2020 г. № 306-ФЗ.

В соответствии с ним конкретизированы две категории инвесторов: квалифицированные и неквалифицированные. Механизм тестирования на получение нового статуса на сегодняшний день недоработан.

Согласно Закону физические лица, признанные квалифицированными инвесторами до 1 апреля 2022 г., сохраняют свой статус в отношении ценных бумаг и тех финансовых инструментов, по которым были признаны таковыми.

В Законе прописана ответственность брокеров за продажу неквалифицированным инвесторам несоответствующих этой категории активов.

Нелегальная продажа таких активов сводится к минимуму. Мерой пресечения таких действий является возмещение всех расходов (комиссии) инвестору и выкуп актива.

Неквалифицированный инвестор в будущем сможет приобрести также иностранные акции, входящие в расчет одного из мировых фондовых индексов, перечень которых планирует утвердить Центральный Банк Российской Федерации к 2021 г. Московская биржа планирует запуск торгов иностранными акциями в рублях. Неквалифицированные инвесторы имеют право участвовать в IPO, в том числе иностранных компаний, при условии листингования компании в котировальных списках Московской биржи.

Для того чтобы неквалифицированному инвестору получить возможность приобретать не доступные финансовые активы, необходимо пройти тестирование по интересующему инструменту или способу инвестирования или получить статус квалифицированного инвестора.

Что касается тестирования, то новый механизм защиты неквалифицированных инвесторов вступит в силу с 1 апреля 2022 г. Стандартный тест предположительно будет состоять из двух блоков. Первый блок будет оценивать опыт инвестирования, второй - знание конкретного инструмента.

Порядок проведения тестирования и перечень вопросов будут утверждаться регулятором. Согласно Закону тестирование проводится бесплатно. Профессиональным инвесторам доступны операции с любыми видами финансовых инструментов.

Кроме того, в приоритетах регулятора создание финансовой стабильности: «...бесперебойное и эффективное функционирование финансового рынка, в том числе процесса трансформации сбережений в инвестиции, его устойчивость к внутренним и внешним шокам» [9].

Следовательно, финансовая стабильность позволит снизить издержки экономики от реализации финансовых рисков, а также возрастет предсказуемость цены капитала для экономических субъектов, что, в свою очередь, позволит обеспечить непрерывность предоставления услуг и сведет к минимуму возможные структурные дисбалансы.

Проведенное исследование позволило доказать высокий степень инвестиционной безопасности, обеспеченной государством. Так, для физического лица как инвестора предусмотрена защищенность от финансовых шоков самой системой, а 
это позволяет снизить премию за системный риск и инструмент становится доступнее для потребителя.

$$
* * *
$$

1. Гражданский кодекс Российской Федерации (часть первая)" от 30.11.1994 N 51-Ф3 [Интернет источник] СПС Консультант Плюс // (Режим доступа http://www.consultant.ru/document/cons_doc_LAW_5142/) (Дата обращения 03.04.2021);

2. Федеральный закон «О внесении изменений в Федеральный закон«О рынке ценных бумаг» и отдельные законодательные акты Российской Федерации» от 31 июля 2020 г. № 306-Ф3 [Интернет источник] СПС Консультант Плюс // (Режим доступа http://www.consultant.ru/document/cons_doc_LAW_34237/) (Дата обращения 03.04.2021)

3. Федеральный закон «О привлечении инвестиций с использованием инвестиционных платформ и о внесении изменений в отдельные законодательные акты Российской Федерации» от 2 августа 2019 г. № 259-Ф3 [Интернет источник] СПС Консультант Плюс // (Режим доступа http://www.consultant.ru/document/cons_doc_LAW_75832/) (Дата обращения 03.04.2021)

4. Федеральный закон "Об инвестиционных фондах" от 29.11.2001 N 156-ФЗ (последняя редакция) [Интернет источник] СПС Консультант Плюс // (Режим доступа http://www.consultant.ru/document/cons_doc_LAW_34237/) (Дата обращения 03.04.2021)

5. Федеральный закон "О Центральном банке Российской Федерации (Банке России)" от 10.07.2002 N 86-Ф3 (последняя редакция) [Интернет источник] СПС Консультант Плюс // (Режим доступа: http://www.consultant.ru/document/cons_doc_LAW_19671/ ) (Дата обращения 03.04.2021);

6. Федеральный закон «Об инвестировании средств для финансирования накопительной части трудовой пенсии» от 24 июля 2002 г. № 111-Ф3 [Интернет источник] СПС Консультант Плюс // (Режим доступа http://www.consultant.ru/document/cons_doc_LAW_34457/) (Дата обращения 03.04.2021)

7. Федеральный закон "О рынке ценных бумаг" от 22.04.1996 N 39-Ф3 (последняя редакция) [Интернет источник] СПС Консультант Плюс // (Режим доступа httphttp://www.consultant.ru/document/cons_doc_LAW_10148/) (Дата обращения 03.04.2021);

8. Федеральный закон "Об инвестиционной деятельности в Российской Федерации, осуществляемой в форме капитальных вложений" от 25.02.1999 N 39-ФЗ (последняя редакция) [Интернет источник] СПС Консультант Плюс // (Режим доступаhttp://www.consultant.ru/document/cons_doc_LAW_22142/) (Дата обращения 03.04.2021);

9. Основные направления развития финансового рынка Российской Федерации на период 2019 2021 годов Банк России. М., 2019 // https://cbr.ru/content/document/file/71220/main_directions.pdf

\section{Меркель Е.А. \\ Проблема в понимании состава административного правонарушения за неисполнение законными представителями несовершеннолетних обязанностей по содержанию и воспитанию несовершеннолетних ФГАОУ ВО «Южно-Уральский государственный университет (НИУ)» (Россия, Челябинск)}

doi: $10.18411 / \mathrm{sr}-10-04-2021-81$

\section{Аннотация}

В статье анализируется состав административного правонарушения за неисполнение законными представителями несовершеннолетних обязанностей по содержанию и воспитанию несовершеннолетних, предусмотренного ст. 5.35 Кодекса Российской Федерации об административных правонарушениях. Рассматриваются недостатки действующей редакции ст. 5.35 Кодекса Российской Федерации об административных правонарушениях, а также вопрос понимания различных подходов в восприятии и понимании ненадлежащего исполнения законными представителями несовершеннолетних обязанностей по содержанию и воспитанию несовершеннолетних.

Ключевые слова: Кодекс Российской Федерации об административных правонарушениях, административные правонарушения, административная ответственность, законные представители, несовершеннолетние. 